American Journal of Applied Sciences 8 (12): 1343-1348, 2011

ISSN 1546-9239

(C) 2011 Science Publications

\title{
Risk Factors to Alcohol Law Violations in the Community: Quasi-Experimental Study
}

\author{
${ }^{1}$ Wuttiphong Phakdeekul, ${ }^{1}$ Pramote Thongkrajai, \\ ${ }^{1}$ Peem Eiamprapai and ${ }^{2}$ Manop Kanato \\ ${ }^{1}$ Department of Medicine, Faculty of Medicine, \\ Mahasarakham University, Maha Sarakham , 44000, Thailand \\ ${ }^{2}$ Department of Community Medicine, Faculty of Medicine, \\ Khon Kaen University, Khon Kaen , 40002, Thailand
}

\begin{abstract}
Problem statement: Alcohol-related health problems such as chronic and acute diseases, accidents/injuries and social problems are well recognized. Although many countries including Thailand enact laws to control alcohol problems, missing data in Thailand cannot reveal efficacy of law enforcement and compliance with the public. The aim of this study was to investigate the proportion of Thai people violating alcohol laws and factors affecting such law violations, then to develop a prevention model based on this information. Approach: This quasi-experimental study was conducted in two areas of Khon Kaen province, North Eastern Thailand. The sample comprised people aged $\geq 10$ years that were dichotomized into an experimental group and control group. Data were analyzed using descriptive and inferential statistics to identify any significant differences following introduction of the prevention model. Factors affecting law violation were analyzed by odds ratio and logistic regression model. Qualitative data were analyzed by content analysis. Results: The proportion of people violating alcohol laws was $93.8 \%$. This was categorized into 5 violation aspects: $88.4 \%$ in respect to time, $84.5 \%$ regarding advertising, $78.6 \%$ regarding customer age, $71.7 \%$ regarding place and $65.5 \%$ regarding alcohol sales campaigns. Factors that had a statistically significant effect on alcohol law violations were physical, bio-sociological, social and psychological in nature. After the interventions were implemented, public knowledge and attitudes were improved. Especially, the proportion of alcohol law violations was reduced from 93.8-72.1\%. Alcohol sales in temples, schools and gas stations were significantly reduced, as was alcohol advertising (all p<0.0001). Conclusion/Recommendations: A prevention model was developed that could potentially decrease alcohol law violations throughout Thailand.
\end{abstract}

Key words: Law violation, risk factors, prevention model, quasi-experimental, gas stations, World Health Organization (WHO), acute disease, accidents/injuries, alcohol consumption

\section{INTRODUCTION}

Alcohol-related health problems are well recognized. In a World Health Organization (WHO) study of 118 countries, it was shown that there are 76.3 million cases of alcohol-related morbidity and 1.8 million alcohol-related deaths each year. These are attributable to chronic and acute disease and accidents/injuries (Jones et al., 2007; Devieux et al., 2009; Hove et al., 2010). Consumption of alcohol can also lead to social and economic problems and crime. Furthermore, alcohol consumption is increasing. Between 1961 and 2004, alcohol consumption increased 8-fold from 0.26-8.47 L per person per year. Several studies found that consumption of alcohol is largely causative of crime; alcohol use is a leading factor of social problems such as unemployment, loss of income, homelessness and adolescent problems (Schwinn and Schinke, 2010). According to criminology and sociology disciplines important factors influencing this problem are physical, bio-sociological, psychological and social in nature (Mannheim, 2003; Loxley and Carruthers, 2004). Advertising is recognized as the most important factor contributing to alcohol use, especially when broadcast during live sport games. Thus policies to solve the alcohol problem must 
include changing people's values as well as health education and measures to control drunken behavior. Awareness of this is increasing and several countries are developing policies to restrict alcohol advertising. Hence handling of the alcohol problem should begin with national policy, because this is important to drive implementation and demonstration of public health care (Bruun, 1975). In 1979, WHO recognized the importance of alcohol-related problems and distributed guidelines for alcohol control policies to member countries. This was shortly followed by the announcement of implementation of appropriate alcoholrelated policies in member countries (WHO, 2004).

Even though profits from alcohol sales benefit the country and alcohol consumption is an integral part of Thai customs (Abramson et al., 2006) and ceremonies, it also causes many negative effects that can be improved by implementation of effective alcohol regulations in the law. According to WHO statistics Thailand was the 50th largest consumer of alcohol in 1998 and consumption is increasing (WHO, 2004). Importantly, increasing numbers of young drinkers are being seen; new policies or measures to control alcohol consumption are clearly needed (Brown et al., 2005; WHO, 2004; Malow et al., 2007).

Legislation is one measure by which the alcohol problem can be curtailed (WHO, 2004; Kajondharma et al., 2004). Alcohol laws can be devised to reduce the negative effects of alcohol on health, society and the economy. However, prevention of alcohol law violations is difficult to achieve (Matsushita and Higuchi, 2007; Momani, 2010). The objectives of the present study were to study the type and proportion of alcohol law violations, to investigate factors associated with violation of alcohol law and to develop a prevention model to reduce alcohol law violations.

\section{MATERIALS AND METHODS}

This quasi-experimental study was conducted in 2 areas of Khon Kaen province, North Eastern Thailand. The sample consisted of 1088 persons aged >10 years who were dichotomized into an experimental group and a control group each comprising 544 people by systematic random sampling. The experimental period lasted 17 months during 2009-10. This study was divided into three phases as follows: Studying community phase including collection of quantitative and qualitative data to analyze problems in the operating phase; implementation phase including intervention activities such as brainstorming meeting, identifying situation awareness problems, project planning and preparation of community rules including input from Buddhist groups, local organizations, entrepreneur groups, government officials, student and youth groups and members of the general public (known as Public hearing, Supporting for materials management budget, Health education, Empowerment to enforce regulations and laws, Enforcement of government officials, making a Commitment agreement to the operators of shops and analysis performance assessment and Evaluation; PSHEECE model. That is, all sectors of government, private and public participation in the formulation of the model to resolve a alcohol law violation). Figure 1 and a monitoring and evaluation phase including survey data in the experimental area and control area.

Data management and measurement: The quality of quantitative data was controlled by the test of content validity and linguistic appropriateness. The quality of the data was controlled from the beginning and rechecked immediately following completion. If there were any mistakes, the data were edited. Data were then input into 2 computers by 2 people and parallel-checked for correctness. Qualitative data were triangulationchecked by finding the reliability from various sources and categories of people. The Between-Method of methodological triangulation, which was the interview and environment observation, was applied to check the data.

Quantitative data were analyzed by descriptive statistics such as mean, median, standard deviation, minimum value, maximum value and range. With inferential statistics the data were analyzed by comparing the difference between independent and dependent variables of the interval scale. Differences of performance were compared between the experimental and control areas.

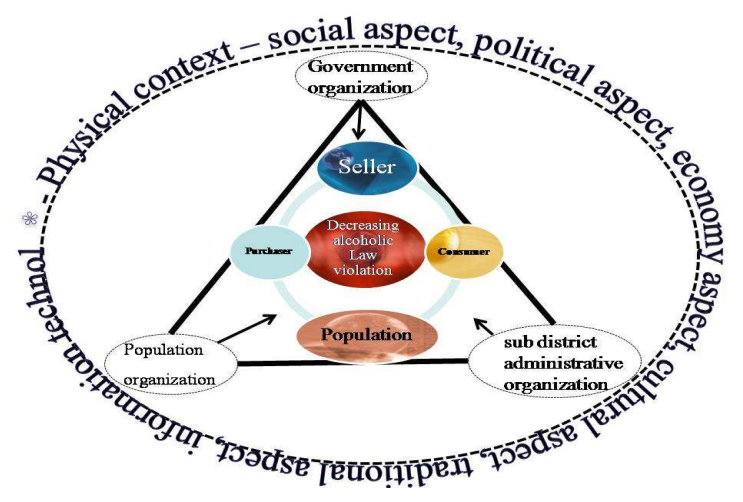

Fig. 1: Our model developed to prevent alcohol law violations 
In the case of abnormal data enumeration, the Independent Sample T-test (Mann-Whitney U Test) was used to compare differences between the results of pre- and post- project conduct. In the case of dependent variables, the McNemar Chi-Square was used. The Pvalue statistic of Pearson Chi-Square was used to analyze the risk factor of alcohol law violations. In the case of univariate analysis, odds ratios and their $95 \%$ confidence interval were used. For multivariate analysis logistic regression was used to identify factors (population character, physical, psychological and society) affecting alcohol law violations. For content analysis the data were classified by coding the number as each type of the data to compare the difference. Finally, inductive data were concluded.

This study was approved by the ethics committee of Mahasakham University in July 2008 (no. 0047/2551).

\section{RESULTS}

Characteristics of participants: Experiment and control areas were similar in aspect such as way of life, career, transportation and customs. The ratio of men and women was 51.7: 48.3, which was similar to that of the population in the area (50.1: 49.9). The age distribution was from 10-88 years. Average age was 41.6 (median, 42; SD, 16.1; IQR, 23.0) years. The sample was divided into two groups by age such as 1020 years $(14.3 \%)$ and $>20$ years $(85.7 \%)$. Among them $41.9 \%$ were agriculturist, $21.2 \%$ employee and $13.1 \%$ student. The minimum and maximum monthly income was $\$ 19.5$ and $\$ 1858.7$; average was $\$ 148.4$ (median, \$101.4; SD, 224.5; IQR, 152.1).

Proportion of alcohol law violations and factors affecting them: The proportion of people violating alcohol laws was $93.8 \%$. Violations could be divided into five categories such as those relating to time (88.4\%), advertising (84.5\%), underage drinking (78.6\%), location of drinking ( $71.7 \%$ in temples, $45.8 \%$ in government offices and $45.8 \%$ in gas stations) and alcohol sales promotions $(65.5 \%)$. Statistically significant factors contributing to breaches of alcohol law were physical, bio-sociological, social and psychological. Regarding physical factors, the rural population was 4 times more at risk than the urban population $\left(\mathrm{OR}_{\mathrm{adj}}, 4.33\right.$; $\left.95 \% \mathrm{CI}[1.45,12.99] ; \mathrm{p}=0.009\right)$. The population living near liquor stores was 3 times more at risk $\left(\mathrm{OR}_{\mathrm{adj}}, 3.30 ; 95 \% \mathrm{CI}[1.29,8.40] ; \mathrm{p}=0.049\right)$.

Regarding bio-sociological factors, the population educated to primary school level was 12 times more at risk $\left(\mathrm{OR}_{\mathrm{adj}}, 12.66 ; 95 \% \mathrm{CI}[2.27,13.43] ; \mathrm{p}=0.004\right)$ whereas that aged $<20$ years was 10 times more at risk $\left(\mathrm{OR}_{\mathrm{adj}}, 10.14 ; 95 \% \mathrm{CI}[1.39,13.84] ; \mathrm{p}=0.022\right)$. Men were 3 times more likely than women to have violations and those with monthly incomes $\geq \$ 606$ were twice as likely as those whose income was $<\$ 606$.

As for social factors, agriculturists were 4 times more at risk than people in other careers $\left(\mathrm{OR}_{\mathrm{adj}}, 4.26\right.$; 95\% CI [1.08, 16.73]; $\mathrm{p}=0.038)$. Celebrations also contributed to alcohol consumption. There were celebrations in each community an average of 4 times/month. In $70.9 \%$ of cases, these celebrations occurred in the morning. During celebrations, alcohol was purchased, sold and consumed $88.3 \%$ of the time (at $70.5 \%$ of festivals and $58.5 \%$ of funerals).

As for psychological factors, people with a poor attitude to alcohol were 5 times more at risk $\left(\mathrm{OR}_{\mathrm{adj}}\right.$, 4.78; 95\%CI [1.58, 14.49]; $\mathrm{p}=0.006)$. Of the sample population $99.4 \%$ had no knowledge of alcohol laws and $77.6 \%$ believed that enforcing alcohol law conflicted with their customs (Table 1).

The most important factor linked to alcohol law violations was physical environment, that is, the distribution of liquor stores in the community.

If the distance between liquor stores and the person's residence was not far, people could obtain alcohol more easily. In addition, social factors such as customs and careers influenced the likelihood of alcohol law violations. This is of concern because children are likely to learn this kind of alcohol use behavior from their family and community. Psychological factors were also linked to law violations; lack of knowledge about alcohol law was highlighted and the relaxed attitude of officials towards the law may have contributed because the communities lack role models and clear rules. The above factors are summarized in Fig. 2.

Efficiency of the model in preventing alcohol law violations: Activities implemented from the model were assessed for appropriateness with respect to area, resources used and impact on community life. In all, $89.3 \%$ of the population accepted that the model addressed community needs and also the vision of the local policy. However, because as many as $78.1 \%$ of people disagree with the use of local laws and regulations to control alcohol problem, $21.9 \%$ objected to the model on the grounds that it conflicted with their customs and way of life.

The model was evaluated by comparing differences between the results before and after introduction of the model. The average population attitude value increased by 5.5-6.3 folds (95\% CI, [5.2, 6.6]) in the period after versus before introduction (Table 2). 
Am. J. Applied Sci., 8 (12): 1343-1348, 2011

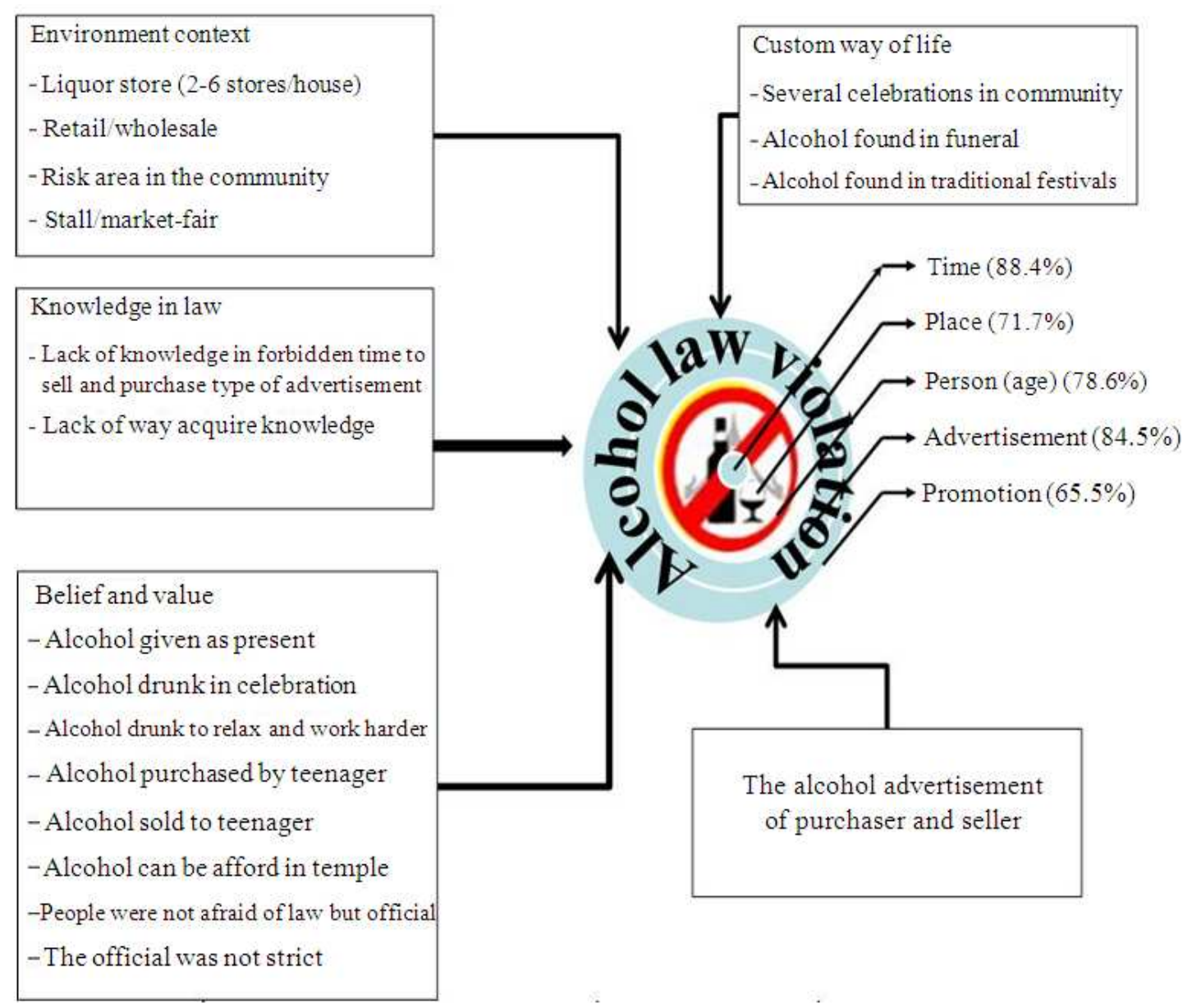

Fig. 2: Factors concluded to have affected alcohol law violations

Table 1: Variables affecting alcohol law violations (with adjustment of interactive weight)

\begin{tabular}{lcccc}
\hline Variable & Crude OR & Adjusted OR & $(95 \% \mathrm{CI})$ & $\mathrm{p}$ \\
\hline Living area (rural and urban) & 1.23 & 4.33 & $(1.45,12.99$ & $0.009^{*}$ \\
Distance between liquor stores and residence $(<500$ or $>500 \mathrm{~m})$ & 2.65 & 3.3 & $(1.29,8.40)$ & $0.012^{*}$ \\
Time of alcohol drinking $(11.00 \mathrm{am}-14.00 \mathrm{pm}$ and $17.00-24.00 \mathrm{pm})$ & 1.41 & 2.44 & $(1.02,5.95)$ & $0.049^{*}$ \\
Experiencing drinking & 1.12 & 10.14 & $(1.39,13.84)$ & $0.022^{*}$ \\
Education level & 1.53 & 12.66 & $(2.27,17.43)$ & $0.004^{*}$ \\
Attitude towards alcohol laws & 14.34 & 4.78 & $(1.57,14.49)$ & $0.006^{*}$ \\
Career & 0.64 & 4.26 & $(1.08,16.73)$ & $0.038^{*}$
\end{tabular}

*: Significant associations $(\mathrm{p}<0.05)$

Table 2: Comparison of knowledge and attitudes towards alcohol laws between experimental and control area before and after introduction of the model $\begin{array}{ll}\text { Levene's test for } & 95 \% \text { CI of the }\end{array}$ equality of variances t-test for equality of means Difference

\begin{tabular}{|c|c|c|c|c|c|c|c|c|c|c|}
\hline & & & \\
\hline & & \multicolumn{9}{|c|}{$\begin{array}{lll}\text { Mean } & F & \text { Sig. }\end{array}$} \\
\hline Variables & \multicolumn{10}{|c|}{ Knowledge } \\
\hline \multirow{2}{*}{\multicolumn{11}{|c|}{$\begin{array}{l}\text { Experiment Area } \\
\text { Control Area }\end{array}$}} \\
\hline & & & & & & & & & & \\
\hline \multicolumn{11}{|l|}{ Attitude } \\
\hline \multicolumn{11}{|l|}{ Experiment Area } \\
\hline Control Area & 5.25 & & & & & & & & & \\
\hline
\end{tabular}

*: Significant associations $(\mathrm{p}<0.05)$ 
Am. J. Applied Sci., 8 (12): 1343-1348, 2011

Table 3: Comparison of alcohol law violations before and after introduction of the model

\begin{tabular}{|c|c|c|c|c|c|c|}
\hline \multirow[b]{3}{*}{ Type of alcohol law violation } & \multicolumn{4}{|c|}{ Alcohol law violation } & \multirow[b]{3}{*}{ OR $(95 \% \mathrm{CI})$} & \multirow[b]{3}{*}{$\mathrm{p}$} \\
\hline & \multicolumn{2}{|c|}{ Experimental area $(n=544)$} & \multicolumn{2}{|c|}{ Control area $(n=544)$} & & \\
\hline & Before $\mathrm{n}(\%)$ & After $\mathrm{n}(\%)$ & Before $\mathrm{n}(\%)$ & After $\mathrm{n}(\%)$ & & \\
\hline $\begin{array}{l}\text { Time violation (other } 11.00-14.00 \\
\text { pm. } 17.00-24.00 \mathrm{pm} .)\end{array}$ & $424(78.0)$ & $389(71.5)$ & $413(76.0)$ & $427(78.5)$ & $4.72(1.99,12.50)$ & $<0.0001 * *$ \\
\hline Sell to the junior citizen lowers 20 year & $345(63.4)$ & $301(55.4)$ & $345(63.4)$ & $351(65.4)$ & $3.46(1.65,7.25)$ & $<0.0001^{* *}$ \\
\hline Place violation (in temple) & 196(36.1) & 196(36.1) & $180(33.1)$ & 191(35.2) & $16.84(3.96,71.56)$ & $<0.0001 * *_{-}$ \\
\hline Place violation (in school or official place) & $288(52.9)$ & $270(49.6)$ & $289(53.2)$ & $380(69.6)$ & $3.66(1.27,10.58)$ & $<0.0001 * *$ \\
\hline Place violation (in petrol stations) & $416(76.4)$ & $345(63.4)$ & $406(74.7)$ & $399(73.4)$ & $1.11(1.71,2.10)$ & $<0.0001 * *$ \\
\hline Alcohol given as reward & $385(70.7)$ & $316(58.1)$ & $391(71.8)$ & $372(68.3)$ & $2.01(1.06,4.28)$ & $<0.0001 * *$ \\
\hline Alcohol discounted & $362(66.5)$ & $335(61.7)$ & $353(64.8)$ & $388(71.4)$ & $1.32(1.05,2.67$ & $<0.0001 * *$ \\
\hline Alcohol sold at stall & $259(47.6)$ & $224(41.1)$ & $276(50.7)$ & $311(57.1)$ & $2.29(1.21,4.36)$ & $<0.0001^{* *}$ \\
\hline Alcohol advertisement & $245(45.0)$ & $196(36.0)$ & $262(48.2)$ & $355(56.3)$ & $1.84(1.01,3.36)$ & $<0.0001 * *$ \\
\hline
\end{tabular}

**: Significant associations $(\mathrm{p}<0.0001)$

In addition, all categories of alcohol law violation decreased substantially. These included violations of alcohol law relating to time, consumption of alcohol in temples, government offices and petrol stations, sale of alcohol to people below the legal age limit, illegal sales promotions including sale from stalls and discounted alcohol and illegal advertising.

The overall proportion of alcohol law violations decreased from $90.7-72.1 \%$ following implementation of the model. Behavior towards alcohol law violation was decreased in every aspect (Table 3).

\section{DISCUSSION}

Studies by WHO show that most countries have alcohol laws, although the level of enforcement of these laws varies (Brown et al., 2005; WHO, 2004) In addition, studies in many countries have found that the proportion of alcohol violations varies at $45.8-64.5 \%$ (Al-Swelmeen, 2006). On the other hand, the present study found that the proportion of alcohol law violations in the Khon Kaen province of Thailand was 93.8\%. Several important risk factors were identified for this province including bio-sociological factors such as education level and physical factors such as distance between liquor store and residence. In addition, this study also found that the public has rapid access to the liquor stores; the average time was $4.3 \mathrm{~min}$. Other factors include customs and culture, which is in line with criminology and sociological ideas (Mannheim, 2003; Lieberman, 1973; WHO, 2004). Another important finding of this study was that local social and family influence on preventing violations was weak; there were many popular activities in the family or community lifestyle that included alcohol consumption, which are not a good role model for young people. In addition, consumer volume increased possibly because alcoholic beverage-producing companies develop advertising strategies that invite people to buy and consume more alcohol.
The key violation of alcohol laws was ignorance of law, habits of people and lifestyle of the people in conflict with national legislation. If these factors are not resolved well by the community and government, alcohol-related health problems will remain or worsen. Therefore measures that effectively control alcohol consumption must integrate many measures and work under participation of associated networks (WHO, 1981) WHO/UNICEF. The government should revise laws in line with the lifestyle of the people based on validated data from specialized organizations and networks.

This study developed a solution to the above problems by giving priority to local organizations, which coordinated activities with many associated networks in the area. They participated by planning to solve outstanding problems corresponding to the requirements of the community by constructing a PSHEECE model. Application of this model could decrease alcohol law violations from $93.8-72.1 \%$. These activities are consistent with the notion of participation and empowerment of people as most effective means of bringing about societal change (Cohen and Uphoff, 1980; Stringer, 2007; Shrivastava and Tandon, 1982). They could choose to modify their own health behavior in association with organizations and the community and cooperated in integration with associated network including government, NGOs and community leaders.

\section{CONCLUSION}

Our model was effective in increasing knowledge of alcohol among the population and changing people's attitudes and behavior in a positive way. We were able to identify risk factors related to distribution in rural area, other high-risk areas, people with low education levels, agriculturists and people with negative attitudes towards alcohol laws. The government should increase monitoring of alcohol laws and their enforcement. Especially, areas that often hold celebrations and have multiple liquor stores should be 
targeted and community organizations encouraged reducing alcohol law violations.

\section{ACKNOWLEDGEMENT}

The researchers are very grateful to everyone who participated in the study and thank the reviewers for their comments on an earlier version of this study.

Funding: This research was supported by the Center for Alcohol Study (CAS), the Thai Health Promotion Foundation and Mahasarakham University.

\section{REFERENCES}

Abramson, C.I., W. Howard, M. Zolna, S. Nain and I.S. Aquino et al., 2006. A price survey comparison of alcoholic beverages with the five basic food groups in paraiba, Brazil. J. Soc. Sci., 2: 100-103. DOI: 10.3844/jssp.2006.100.103

Al-Swelmeen, M.M., 2006. The international law classification as an understanding of the built of international law. J. Soc. Sci., 2: 104-107. DOI: 10.3844/jssp.2006.104.107

Brown, S.A., K.G. Anderson, D.E. Ramo and K.L. Tomlinson, 2005. Treatment of adolescent alcoholrelated problems. A translational perspective. Recent Dev. Alcohol, 17: 327-348. DOI: 10.1007/0-306-48626-1_15 PMID: 15789874

Bruun, K. 1975. Alcohol Control Policies in Public Health Perspective. 1st Edn., Finnish Foundation for Alcohol Studies, Helsinki, ISBN: 9789519191300, pp: 106.

Cohen, J.M. and N.T. Uphoff, 1980. Participation's place in rural development: Seeking clarity through specificity. World Deve., 8: 213-235.

Devieux, J.G., R.M. Malow, R. Rosenberg, M. Nair and D.M. Samuels et al., 2009. Borderline personality symptoms and human immunodeficiency virus risk in alcohol and other drug abusing adolescent offenders. Am. J. Infect. Dis., 3: 31-39. DOI: 10.3844/ajidsp.2009.31.39

Hove, M.C., M.R. Parkhill, C. Neighbors, J.M. McConchie and N. Fossos, 2010. Alcohol consumption and intimate partner violence perpetration among college students: The role of self-determination. J. Stud. Alcohol Drugs, 71: 78-85. PMID: 20105417
Jones, D.L., S.M. Weiss, N. Chitalu, O. Villar and M. Kumar et al., 2007. Sexual risk intervention in multiethnic drug and alcohol user. Am. J. Infect. Dis., 3: 169-176. DOI: 10.3844/ajidsp.2007.169.176

Lieberman, F., 1973. Before Addiction: How to Help Youth. 1st Edn., Behavioral Publications, New York, ISBN: 9780877051121, pp: 131.

Loxley, W. and S. Carruthers, 2004. The Prevention of Substance use Risk and Harm in Australia: A Review of the Evidence. 1st Edn., Commonwealth of Australia, Canberra, ISBN: 9780642824820, pp: 315.

Malow, R.M., J. Devieux, R. Rosenberg, M. Nair and R. McMahon et al., 2007. Antisocial psychopathy and HIV risk among Alcohol and Other Drug (AOD) abusing adolescent offenders. Am. J. Infect. Dis., 3: 230-239. DOI: 10.3844/ajidsp.2007.230.239

Mannheim, H., 2003. Comparative Criminology. 2nd Edn., Routledge and Keygan Paul, London, ISBN: 9780415177320, pp: 793.

Matsushita, S. and S. Higuchi, 2007. A review of the neuroimaging studies of Alcoholism. Nihon Arukoru Yakubutsu Igakkai Zasshi, 42: 615-621. PMID: 18240649

Momani, N.M., 2010. Improving Jordan's law towards sustainable solid and hazardous waste management: Lessons from USA's environmental laws. Am. J. Environ. Sci., 6: 338-343. DOI: 10.3844/ajessp.2010.338.343

Schwinn, T.M. and S.P. Schinke, 2010. Preventing alcohol use among late adolescent urban youth: 6year results from a computer-based intervention. J. Stud. Alcohol Drugs, 71: 535-538. PMID: 20553661

Shrivastava, O. and R. Tandon, 1982. Participatory Training for Rural Development. 1st Edn., Society for Participatory Research in Asia, New Delhi, pp: 191.

Stringer, E.T., 2007. Action Research. 3rd Edn., Sage Publications, Thousand Oaks, Calif., London, ISBN: 9781412952231, pp: 279.

WHO, 1981. Global Strategy for Health for all by the Year 2000. 2nd Edn., World Health Organization, Geneva, ISBN: 9789241800037, pp: 90.

WHO., 2004. Global Status Report: Alcohol Policy. 1st Edn., World Health Organization, Geneva, ISBN: 9789241580359, pp: 209. 